\title{
Ionic liquids as formaldehyde-free wood adhesives
}

\author{
Nagisa Nakaya ${ }^{1} \cdot$ Takashi Hosoya $^{1} \cdot$ Hisashi Miyafuji ${ }^{1}$
}

Received: 20 June 2018 / Accepted: 28 September 2018 / Published online: 31 October 2018

(C) The Japan Wood Research Society 2018

\begin{abstract}
Several ionic liquids promote depolymerization of wood components, i.e., polysaccharides and lignin, into low molecular weight compounds, some of which further re-polymerize into resin-like compounds. In this study, the depolymerization/ re-polymerization of wood components in ionic liquids was applied to preparation of plywoods from Japanese cedar (Cryptomeria japonica) veneers by employing ionic liquids as adhesives. The adhesive solution was prepared by mixing an ionic liquid (pyridine hydrochloride ([Py][Cl]), imidazole hydrochloride ([IM][Cl]), or 1-ethylpyridinium chloride ([EtPy] $[\mathrm{Cl}])$ ) with water and D-glucose in various weight ratios. Tensile shear test of the three-ply plywoods prepared from the veneers and the adhesive solution through hot-pressing indicated that the plywood bonded with the [IM][Cl]-based solution ([IM][Cl]/ water/glucose ratio: 9/3/2) exhibited the highest strength. Scanning electron microscope observation on the plywoods suggested that the ionic liquids softened the cell walls of the probably plywood through the depolymerization/re-polymerization reactions and the cell walls were compressed during the hot-pressing process. Entwining of the compressed cell walls and van der Waals force enhanced by the compression were considered to be origins of the adhesion of the veneers.
\end{abstract}

Keywords Ionic liquid $\cdot$ Adhesive $\cdot$ Wood $\cdot$ Bond strength $\cdot$ Tensile shear tests

\section{Introduction}

Ionic liquids are organic salts possessing low melting points around ambient temperatures. As a comparison to general organic solvents, ionic liquids have the characteristics of non-volatility, incombustibility, and high thermal stability [1]. Because of these unique properties, ionic liquids have gathered much attention as a novel solvent and medium for various chemical reactions. In addition, the properties of an ionic liquid can be modified through changing the component cation and/or anion, which broadens their applications.

Ohno and Miyafuji reported that cellulose was dissolved in 1-ethyl-3-methylimidazolium chloride ([EMIM][Cl]) at 100,120 and $140{ }^{\circ} \mathrm{C}$ and depolymerized into low molecular weight (MW) compounds such as cellobiose and glucose. The treatment in [EMIM][Cl] for longer reaction times resulted in the formation of high molecular weight compounds probably due to re-polymerization of the low MW

Hisashi Miyafuji

miyafuji@kpu.ac.jp

1 Graduate School of life and Environmental Sciences, Kyoto prefectural University, 1-5 Hangi-cho, Shimogamo, Sakyo-ku, Kyoto 606-8522, Japan compounds [2]. Miyata and Miyafuji observed similar reaction behavior of cellulose, namely depolymerization of cellulose and re-polymerization of the degraded products, also in 1-ethylpyridinium chloride ([EtPy][Cl] $)$ at $120^{\circ} \mathrm{C}$ [3].

Polymerization is one of the fundamental reactions in curing process of wood adhesives. For instance, during hotpressing of veneers with a phenol-formaldehyde-based adhesive, co-polymerization of phenol and formaldehyde results in the formation of adhesive layers consisting of phenolic structures bridged by formaldehyde-derived $-\mathrm{CH}_{2}-$ moiety. This led us to the idea that ionic liquids can be utilized as a wood adhesive. Although ionic liquids carry no deliberate components contributing to adhesion, the low MW compounds formed upon the degradation of wood in ionic liquids are expected to play roles as the sources of the formation of the adhesive layer through their re-polymerization.

At present, most of wood adhesives such as phenol-formaldehyde, urea-formaldehyde, melamine-urea and resorcinol-formaldehyde resins employ formaldehyde, which is one of risk factors of sick house syndrome [4]. In spite of the current efforts to reduce the amount of formaldehyde diffused from wood adhesives, its complete reduction has not been made yet. In the adhesion process with ionic liquids, on the other hand, the low MW 
compounds are procured in situ during the pressing and their re-polymerization to form the adhesive layer does not require formaldehyde. Thus, our idea of ionic liquids as a wood adhesive can lead to development of a novel formaldehyde-free wood adhesive. To this end, this study prepared several ionic liquid-based wood adhesives and investigated their performance. Mechanisms involved in the adhesion are also discussed mainly based on observation of the adhesive layer with electron microscopic techniques.

\section{Materials and methods}

\section{Chemicals}

Pyridine hydrochloride ([Py][Cl]) and D-glucose were purchased from Wako pure chemical co., Japan. Imidazole hydrochloride $([\mathrm{IM}][\mathrm{Cl}])$ and $[\mathrm{EtPy}][\mathrm{Cl}]$ were purchased from Sigma-Aldrich Japan, Japan and Tokyo chemical industry, co., Ltd., Japan, respectively.

\section{Preparation of adhesive solutions}

Previous papers have reported that some ionic liquids possessing the chloride ion are effective for dissolution of cellulose [5-8]. According to those findings, this study employs [Py][Cl], [IM] [Cl], and [EtPy][Cl] as the sources of the adhesive solution. An ionic liquid $(9 \mathrm{~g})$ was dissolved in $1.0-3.0 \mathrm{~mL}$ of water in a $100-\mathrm{ml}$ glass flask. D-Glucose $(1.0-5.0 \mathrm{~g})$ was then added to the ionic liquid solution and stirred until it became homogeneous. The eventual weight ratio of the ionic liquid, water, and D-glucose in the resulting adhesive solutions is summarized in Table 1. Several types of [EtPy][Cl]-based adhesive solutions (EtPy6-10) were prepared without water (Table 1). In this case, [EtPy][Cl] was heated at $120{ }^{\circ} \mathrm{C}$ to liquid form in a 100 -mL glass flask. A certain amount of D-glucose was successively added to the flask and further heated for $5 \mathrm{~min}$.

\section{Preparation of three-ply plywoods}

Three-ply plywood specimens described in Fig. 1 were prepared according to a standard method (JIS K 6851). Three Japanese cedar (Cryptomeria japonica) veneers
Table 1 Composition of the adhesive solutions prepared in this study

\begin{tabular}{|c|c|c|c|c|c|c|c|}
\hline \multirow[t]{2}{*}{ Ionic liquid } & \multirow[t]{2}{*}{ Name } & \multicolumn{3}{|l|}{ Weight (g) } & \multicolumn{3}{|c|}{ Spread rate $\left(\mathrm{g} / \mathrm{m}^{2}\right)^{\mathrm{a}}$} \\
\hline & & Ionic liquid & Water & Glucose & Ionic liquid & Water & Glucose \\
\hline \multirow[t]{6}{*}[\mathrm{Py}]{$[\mathrm{Cl}]$} & Py0 & 9 & 2 & 0 & 91 & 20 & 0 \\
\hline & Py1 & 9 & 2 & 1 & 90 & 20 & 10 \\
\hline & Py 2 & 9 & 2 & 2 & 92 & 21 & 21 \\
\hline & Py3 & 9 & 2 & 3 & 91 & 20 & 30 \\
\hline & Py4 & 9 & 2 & 4 & 91 & 20 & 40 \\
\hline & Py5 & 9 & 2 & 5 & 90 & 20 & 50 \\
\hline \multirow[t]{6}{*}[\mathrm{IM}]{$[\mathrm{Cl}]$} & IM0 & 9 & 3 & 0 & 83 & 28 & 0 \\
\hline & IM1 & 9 & 3 & 1 & 83 & 28 & 9 \\
\hline & IM2 & 9 & 3 & 2 & 83 & 28 & 18 \\
\hline & IM3 & 9 & 3 & 3 & 83 & 28 & 28 \\
\hline & IM4 & 9 & 3 & 4 & 83 & 28 & 37 \\
\hline & IM5 & 9 & 3 & 5 & 82 & 27 & 46 \\
\hline \multirow[t]{11}{*}[\mathrm{EtPy}]{$[\mathrm{Cl}]$} & EtPy0 & 9 & 1 & 0 & 100 & 11 & 0 \\
\hline & EtPy1 & 9 & 1 & 1 & 98 & 11 & 11 \\
\hline & EtPy2 & 9 & 1 & 2 & 100 & 11 & 22 \\
\hline & EtPy3 & 9 & 1 & 3 & 98 & 11 & 33 \\
\hline & EtPy4 & 9 & 1 & 4 & 100 & 11 & 44 \\
\hline & EtPy5 & 9 & 1 & 5 & 99 & 11 & 55 \\
\hline & EtPy6 & 9 & 0 & 1 & 100 & 0 & 11 \\
\hline & EtPy7 & 9 & 0 & 2 & 98 & 0 & 22 \\
\hline & EtPy8 & 9 & 0 & 3 & 100 & 0 & 33 \\
\hline & EtPy9 & 9 & 0 & 4 & 98 & 0 & 44 \\
\hline & EtPy10 & 9 & 0 & 5 & 100 & 0 & 56 \\
\hline
\end{tabular}

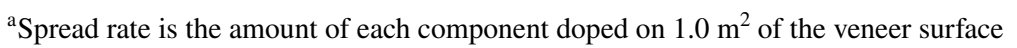




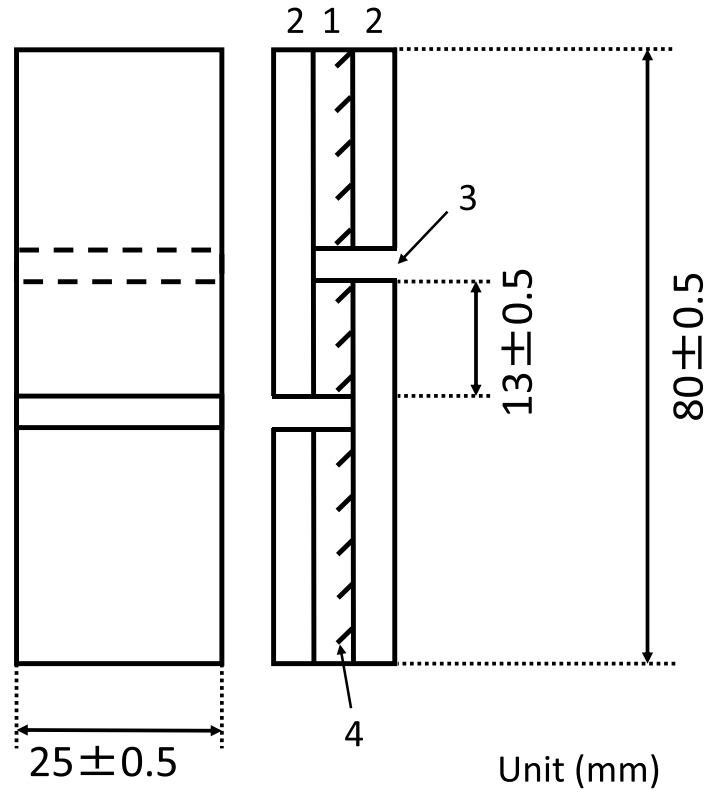

Fig. 1 Three-ply plywood prepared employed for strength evaluation. (1) Core veneer. (2) Surface veneer. (3) Slit. (4) Lathe chuck

with the diameters of $150 \times 150 \times 3 \mathrm{~mm}$ were dried in an oven at $105^{\circ} \mathrm{C}$ for $24 \mathrm{~h}$ and then cooled at $20^{\circ} \mathrm{C}$ in air with $65 \%$ humidity. $2.5-3.7 \mathrm{~g}$ of the ionic liquid solutions were applied to both sides of one of the veneer (Fig. 1) with a rubber roller. This veneer is named "core veneer" hereafter. The core veneer was then stacked between the rest of two veneers (surface veneers) with the grain directions of two adjacent veneers being perpendicular to each other. The three veneers were hot-pressed for 10-120 min at 0.98, 2.9 and 4.9 MPa. Distance bars with $8 \mathrm{~mm}$ thickness were set on both sides of the veneers during the hotpressing. Preparation of the three-ply plywood was carried out one time for each combination of the preparative conditions (type of the solution, pressure, time, etc). Four specimens with each size being $80 \times 25 \times 8 \mathrm{~mm}$ with silts as shown in Fig. 1 were finally cut off from the three-ply plywood prepared.

\section{Evaluation of plywood properties}

After being conditioned for 2 days at $20{ }^{\circ} \mathrm{C}$ and $65 \%$ humidity, tensile shear tests of the specimens were conducted. The bond strength was measured with the loading rate being $1 \mathrm{~mm} / \mathrm{min}$ in accordance with the Japan Industrial Standard (JIS) for the specimens (JIS K 6851). As four specimens are obtained from one plywood sample, the tensile shear tests were performed four times for specimens prepared under the same conditions.
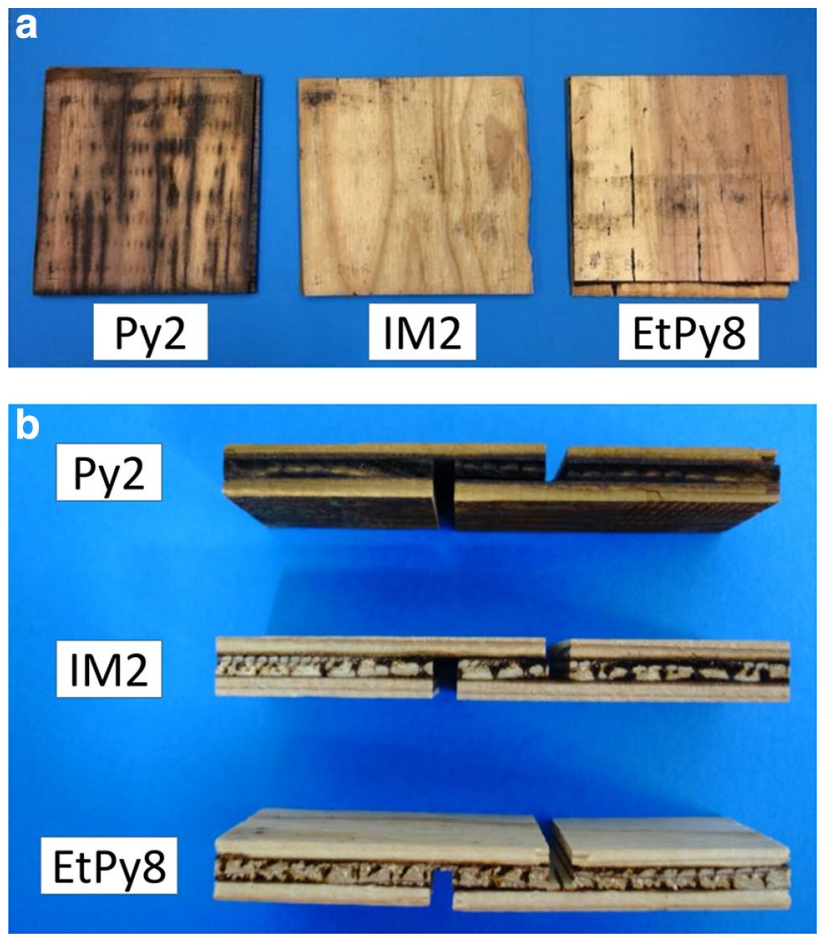

Fig. 2 Images of three-ply plywoods, top view (a) and side view (b), prepared with $[\mathrm{Py}][\mathrm{Cl}]-$, $[\mathrm{IM}][\mathrm{Cl}]-$, and $[\mathrm{EtPy}][\mathrm{Cl}]$-based adhesive solutions (Py2, IM2, EtPy8, respectively, see Table 1 for their composition). Pressing conditions: $180{ }^{\circ} \mathrm{C} / 2.9 \mathrm{MPa} / 60 \mathrm{~min}$

\section{Observation of bond line}

The plywoods bonded with the [Py][Cl], [IM][Cl], and $[\mathrm{EtPy}][\mathrm{Cl}]$ adhesive solutions were surfaced with a sliding microtome (TU-213, Yamato Kohki Industrial Co., Ltd., Saitama, Japan) to prepare $5 \times 5 \times 5$-mm sections for scanning electron microscope (SEM) observation. After dried at $105^{\circ} \mathrm{C}$ for $1 \mathrm{~h}$, the section was mounted on a specimen holder using carbon tape and sputter-coated with Au using a JEOL JFC-1600 auto-fine coater (Japan Electro Optical Laboratory, Tokyo, Japan). The exposed surface was examined with a SEM (Miniscope ${ }^{\circledR}$ TM3030Plus, HITACHI, Japan) at the beam accelerating voltage to $15 \mathrm{kV}$.

\section{Results and discussion}

\section{Appearance of the plywoods and specimens}

Figure 2 shows images of the plywoods prepared with the $[\mathrm{Py}][\mathrm{Cl}],[\mathrm{IM}][\mathrm{Cl}]$, and [EtPy] $[\mathrm{Cl}]$ adhesive solutions at $180{ }^{\circ} \mathrm{C}$ and $2.9 \mathrm{MPa}$ for $60 \mathrm{~min}$. It becomes clear that all plywoods were bonded with each other by the adhesive solutions employed. In all cases, the color of the boundary between the surface and core veneers turned into 
dark-brown. This indicates that the ionic liquid caused degradation reactions, namely the depolymerization of the wood components and their re-polymerization, around the boundary part.

The experiment with the $[\mathrm{Py}][\mathrm{Cl}]$ solution caused the most significant color change than those with the other solutions: even the plywood surface turned into black in the case of $[\mathrm{Py}][\mathrm{Cl}]$. This is probably because the $[\mathrm{Py}][\mathrm{Cl}]$ adhesive solution penetrated the plywood to its surface, by which the reaction of wood occurred on the surface area as well as on the boundary where the solution was at the beginning.

\section{Effect of pressing pressure and time}

We employ many types of the adhesive solutions with various ionic liquids and the ionic liquid/water/D-glucose ratios, as shown in Table 1. In this section, in advance of detailed discussion on the performance of each adhesive solution, we first discuss the effects of the pressing pressure and time on the bond strength of the three-ply plywood with the fixed pressing temperature of $180^{\circ} \mathrm{C}$. Here we employed the [Py] [Cl]-based adhesive solution, Py2 (Table 1), which caused the most intensive color change during the pressing.

Figure $3 \mathrm{a}$ shows the bond strength of the three-ply plywoods pressed at $0.98-4.9 \mathrm{MPa}$ for $60 \mathrm{~min}$. The bond strength increased from 0.19 to $0.52 \mathrm{MPa}$ upon going from the pressing pressure of 0.98-2.9 MPa. However, imposing further pressure to $4.9 \mathrm{MPa}$ decreased the bond strength to $0.37 \mathrm{MPa}$. The maximum bond strength was, therefore, achieved at the pressing pressure of 2.9 MPa.

We then examined dependency of the bond strength on the pressing time at the fixed pressure of $2.9 \mathrm{MPa}$. As shown in Fig. 3b, the bond strength increased from 0.12 to $0.52 \mathrm{MPa}$ when the time was prolonged from 10 to $60 \mathrm{~min}$. Further prolongation to 120 min ended up in the decreased bond strength of $0.39 \mathrm{MPa}$. These results clearly indicate that, at the employed pressure of $2.9 \mathrm{MPa}$ and the temperature of $180^{\circ} \mathrm{C}$, the bond strength becomes maximum at the pressing time of $60 \mathrm{~min}$.

According to the above discussion, we concluded that the optimum pressure and the time were $2.9 \mathrm{MPa}$ and $60 \mathrm{~min}$, respectively. We will thus discuss the performance of various adhesive solutions on the basis of the bond strength of the three-ply plywood prepared at these pressure and time.

\section{Performance of the ionic liquid-based adhesive solutions}

Figure 4a shows the bond strength of the plywoods bonded with the adhesive solutions based on $[\mathrm{Py}][\mathrm{Cl}]$, water, and D-glucose. As $[\mathrm{Py}][\mathrm{Cl}]$ is solid at room temperature, water was added to all adhesive solutions to make them in liquid form. When the plywood was bonded with only $[\mathrm{Py}][\mathrm{Cl}]$
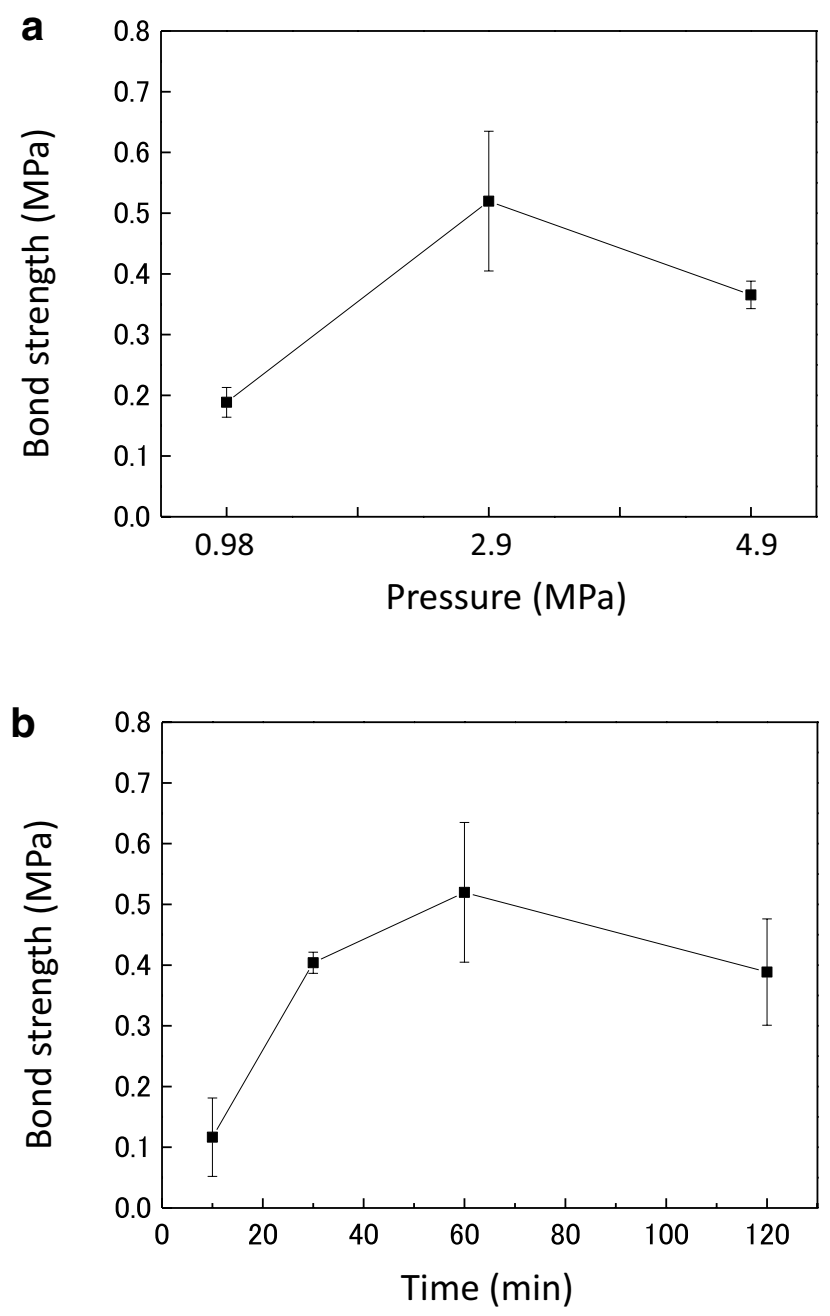

Fig. 3 Effects of the pressure and time on the bond strength of the three-ply plywood prepared at $180{ }^{\circ} \mathrm{C}$ with the Py2 solution (Table 1). Error bars show $95 \%$ confidence interval

and water (9/2/0) [Py][Cl]/water/D-glucose weight ratio, the bond strength was $0.36 \mathrm{MPa}$, indicating that the ionic liquid $[\mathrm{Py}][\mathrm{Cl}]$ itself can act as an adhesive for the plywoods in the presence of water. When D-glucose was added to the adhesive solution to prepare the Py 2 solution with 9/2/2, the bond strength increased to $0.52 \mathrm{MPa}$, meaning that the performance of the adhesive was improved by the addition of D-glucose. When the amount of D-glucose was further increased, however, improvement of the bond strength was not observed. It was, therefore, stated that, in the case of the [Py][Cl]-based adhesive solution, the optimum weight ratio of [Py][Cl], water and D-glucose was 9/2/2.

Figure $4 \mathrm{~b}, \mathrm{c}$ shows the bond strength exhibited by the $[\mathrm{IM}][\mathrm{Cl}] /$ water and [EtPy][Cl]/water-based adhesive solutions. Tendency similar to that for the above [Py][Cl]-based adhesive solution was observed in terms of the addition of D-glucose. For instance, the $[\mathrm{IM}][\mathrm{Cl}] /$ water adhesive 

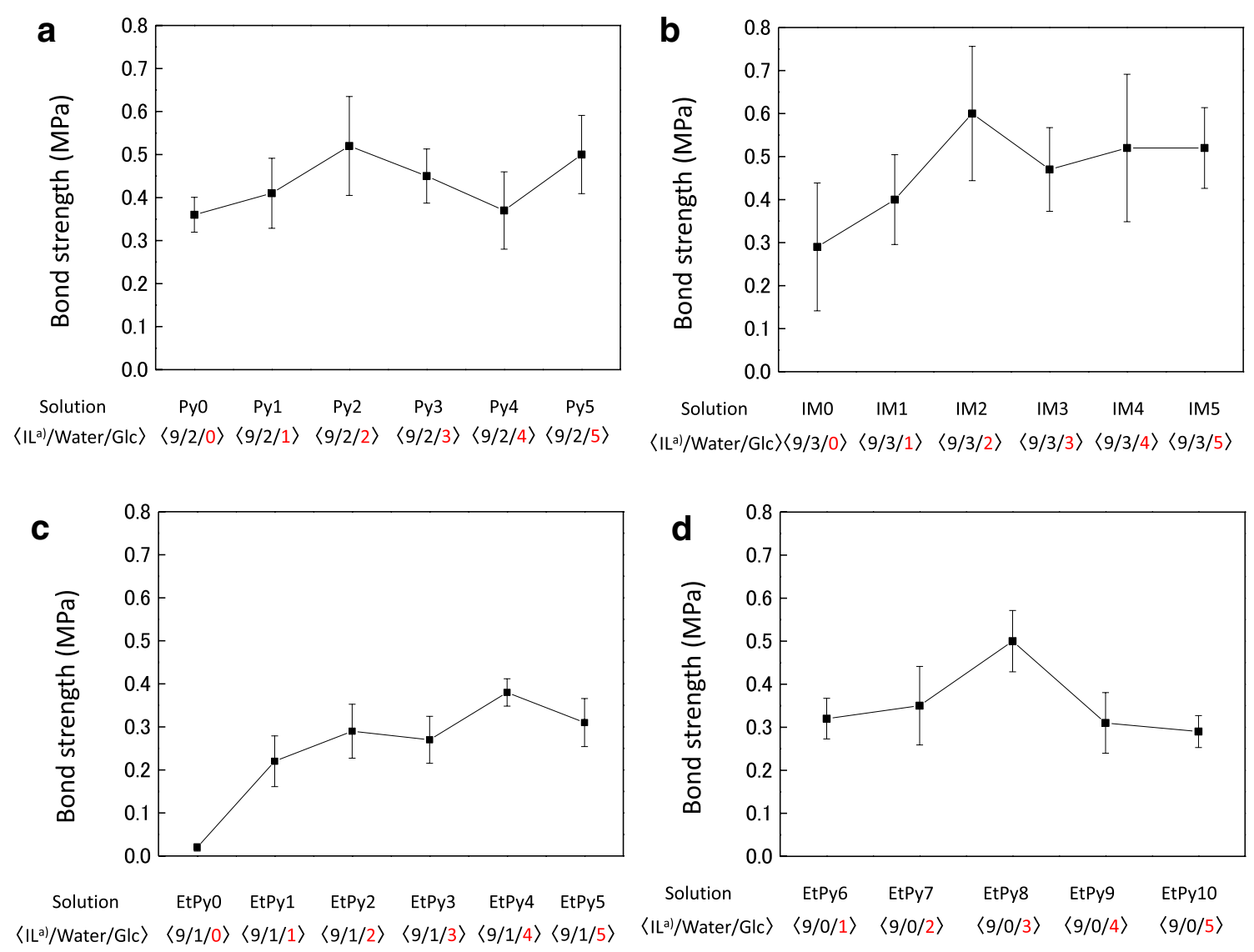

Fig. 4 Bond strengths achieved with [Py][Cl]-based (a), [IM][Cl]-based (b), and [EtPy][Cl]-based (c, d) adhesive solutions with various glucose contents. IL ionic liquid. Error bars show 95\% confidence interval

solution without D-glucose (the IM0 solution) exhibited $0.29 \mathrm{MPa}$ bond strength, which was improved to $0.60 \mathrm{MPa}$ by the addition of D-glucose (the IM2 solution). Increase in the amount of D-glucose, however, did not further improve the bond strength, indicating that the optimum ratio of [IM] [Cl], water, and D-glucose was 9/3/2 (the IM2 solution) in this type of adhesive. Similarly, in the $[\mathrm{EtPy}][\mathrm{Cl}] /$ water system, maximum bond strength of $0.38 \mathrm{MPa}$ was obtained with the $[\mathrm{EtPy}][\mathrm{Cl}] /$ water/D-glucose ratio being 9/1/4 (the EtPy4 solution).

In the case of [EtPy][Cl], we also prepared the adhesive solutions without water addition, as $[\mathrm{EtPy}][\mathrm{Cl}]$ is liquid at room temperature. As shown in Fig. 4d, the bond strength was $0.32 \mathrm{MPa}$ at the [EtPy] $[\mathrm{Cl}]$ and D-glucose ratio of 9:1 (the EtPy6 solution). Similar to the above system with the water addition, the increase in the D-glucose amount to $1 / 3$ of the $[\mathrm{EtPy}][\mathrm{Cl}]$ weight (the EtPy8 solution) resulted in higher bond strength of $0.50 \mathrm{MPa}$, but the bond strength was decreased by further addition of D-glucose. It is also noted that the performance of the adhesive solution was increased by the exclusion of water from the adhesive solution: maximum bond strength was $0.50 \mathrm{MPa}$ without the water addition, which was higher than that exhibited in the presence of water shown above.

As a summary of the above result, the optimum ionic liquid/water/D-glucose ratio was determined to be $9 / 2 / 2$, 9/3/2, and 9/0/3 for the [Py][Cl], [IM][Cl], and [EtPy][Cl] adhesive solutions, respectively: they are Py2, IM2 and EtPy8 solutions (see Table 1; Fig. 4). The bond strength exhibited by these solutions was $0.52 \mathrm{MPa}$ for the [Py] [Cl] solution, $0.60 \mathrm{MPa}$ for the [IM][Cl] solution, and $0.50 \mathrm{MPa}$ for the $[\mathrm{EtPy}][\mathrm{Cl}]$ solution. However, these bond strengths cannot be directly compared to each other, as the amount of the ionic liquid applied to the plywoods is different depending on the solution. We thus leveled the bond strengths to obtain the bonding force of each ionic liquid as listed in Table 2, the bonding forces for [EtPy] $[\mathrm{Cl}],[\mathrm{Py}][\mathrm{Cl}]$ and $[\mathrm{IM}][\mathrm{Cl}]$ were $5.0 \times 10^{3}, 5.7 \times 10^{3}$ and $7.2 \times 10^{3} \mathrm{~N} / \mathrm{g}$, respectively. These value indicate that [IM] $[\mathrm{Cl}]$ exhibited the strongest boning force with the order of the adhesion performance being [IM] $[\mathrm{Cl}]>[\mathrm{EyPy}]$ $[\mathrm{Cl}]>[\mathrm{Py}][\mathrm{Cl}]$. 
Table 2 Bonding force $(\mathrm{N} / \mathrm{g})$ calculated for the ionic liquids according to the results obtained from the Py2, IM2, and EtPy8 solutions

\begin{tabular}{llllc}
\hline $\begin{array}{l}\text { Adhesive } \\
\text { solution }^{\mathrm{a}}\end{array}$ & Based ionic liquid & $\begin{array}{l}\text { Bonding force per ionic } \\
\text { liquid }^{\mathrm{b}}(\mathrm{N} / \mathrm{g})\end{array}$ & $\begin{array}{l}\text { Bond strength } \\
\left(\mathrm{MPa}, \mathrm{MN} / \mathrm{m}^{2}\right)\end{array}$ & $\begin{array}{l}\text { Spread rate of } \\
\text { ionic liquid } \\
\left(\mathrm{g} / \mathrm{m}^{2}\right)\end{array}$ \\
\hline Py2 & {$[\mathrm{Py}][\mathrm{Cl}]$} & $5.7 \times 10^{3}$ & 0.52 & 92 \\
$\mathrm{IM} 2$ & {$[\mathrm{IM}][\mathrm{Cl}]$} & $7.2 \times 10^{3}$ & 0.60 & 83 \\
EtPy8 & {$[\mathrm{EtPy}][\mathrm{Cl}]$} & $5.0 \times 10^{3}$ & 0.50 & 100 \\
\hline
\end{tabular}

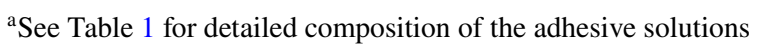

${ }^{\mathrm{b}}$ Bond force was calculated by dividing the bond strength (MPa or $\left.\mathrm{MN} / \mathrm{m}^{2}\right)$ with the spread ratio $\left(\mathrm{g} / \mathrm{m}^{2}\right.$, see Table 1 for its definition) and accordingly has the dimension of N/g

\section{Observation of the bond line}

Figure 5 shows SEM images of the three-ply plywoods prepared with the $[\mathrm{Py}][\mathrm{Cl}],[\mathrm{IM}][\mathrm{Cl}]$, and $[\mathrm{EtPy}][\mathrm{Cl}]$-based adhesive solutions, the Py2, IM2, and EtPy8 solutions, with which the maximum bond strength was achieved (see Fig. 4). In all cases, the layer consisting only of the adhesive solution was not observed between the surface and core veneers, indicating that all adhesive solutions applied were absorbed into the veneer during the pressing process.

As presented in Fig. 5a, crushed tissues were observed in the surface veneer as indicated by circle when the [Py] $[\mathrm{Cl}]$ adhesive solution was employed. Also, the boundary between the surface and core veneers contained significant amount of compressed cells. These results strongly suggest that the adhesive solution penetrated the veneers and enhanced its degradation, resulting in softening of the cell walls of the veneers. This consideration is supported also by the fact that the color of entire veneer turned into dark-brown after the pressing, as shown in Fig. 2.

In the case of the $[\mathrm{IM}][\mathrm{Cl}]$-based adhesive solution (the IM2 solution), as shown in Fig. 5b, the boundary between the surface and core veneers was substantially compressed, as observed for the [Py][Cl]-based solution (the Py2 solution) shown in Fig. 5a. On the other hand, the crushing of entire surface veneer observed for the [Py][Cl]-based solution was not very extensive in the case of [IM][Cl]-based solution. This is in accordance with the result that, for the $[\mathrm{IM}][\mathrm{Cl}]$ solution, darkening of entire veneer was not observed during the pressing although the boundary between the surface and core veneers became dark-brown. These results suggest that penetration of the $[\mathrm{IM}][\mathrm{Cl}]$ adhesive solution through wood tissue was not as intensive as that of the $[\mathrm{Py}][\mathrm{Cl}]$ solution and accordingly the degradation of the cell wall was limited to around the boundary. For the [EtPy] [Cl] solution (the EtPy8 solution), as shown in Fig. 5c, the compression of the cell walls around the boundary and the crushing of the tissue of the surface veneer were the least intensive of the three adhesive solutions.

The highest bond strength, as discussed in Table 2, was obtained for the $[\mathrm{IM}][\mathrm{Cl}]$ adhesive solution, which cause the moderate crushing of the cell walls. The bond strength was decreased in the [EtPy][Cl] solution, which caused less intensive crushing. It is thus stated that crushing of the cell walls are closely related to the adhesion ability of the ionic liquid solutions. It is likely that entwining of the crushed cell walls getting in contact closely with each other is one of the major factors of the bonding between the veneers [9]. Another factor would be van der Waals force enhanced by the compression of the cell walls.

These considerations may lead to the idea that the [Py] [Cl] solution causing the most intensive crushing (Fig. 5a) should exhibit the highest bond strength, but the bond strength of the Py2-bonded sample was smaller than that of the IM2-bonded one (Table 2). This is because-although the performance of the Py 2 solution is the highest from the view point of adhesion itself-the $[\mathrm{Py}][\mathrm{Cl}]$ treatment caused so high compression and crushing of the cell walls that it weakened the strength of the veneer. In fact, as shown in Fig. 6, the tensile shear test for the sample bonded with the Py2 solution resulted in breaking down of inner parts of the veneer (wood failure: $40-50 \%$ from the appearance in Fig. 6), whereas the IM2 and EtPy8-bonded samples fractured along the boundary of the veneers (wood failure: $\sim 0 \%$ ). The other $[\mathrm{Py}][\mathrm{Cl}]$-based adhesives (Table 1) frequently caused breaking down of the veneer after the tensile shear test. These results strongly suggest that penetration of the ionic liquid into the veneer plays substantial role in the adhesion of the ionic liquid solutions, and hence pressing conditions should be carefully decided to control the penetration.

\section{Conclusions}

We investigated the shear bond strengths of the three-ply plywood bonded with the adhesive solutions based on the three types of the ionic liquids, [Py][Cl], [IM][Cl], and [EtPy][Cl]. All adhesive solutions exhibited adhesion ability through enhancing the polymerization occurring mainly around the boundary between the surface and core veneers. The addition of glucose further strengthened the bonding between the veneers, with the most adequate ionic liquid/ glucose ratio being dependent on the type of the ionic liquid. 

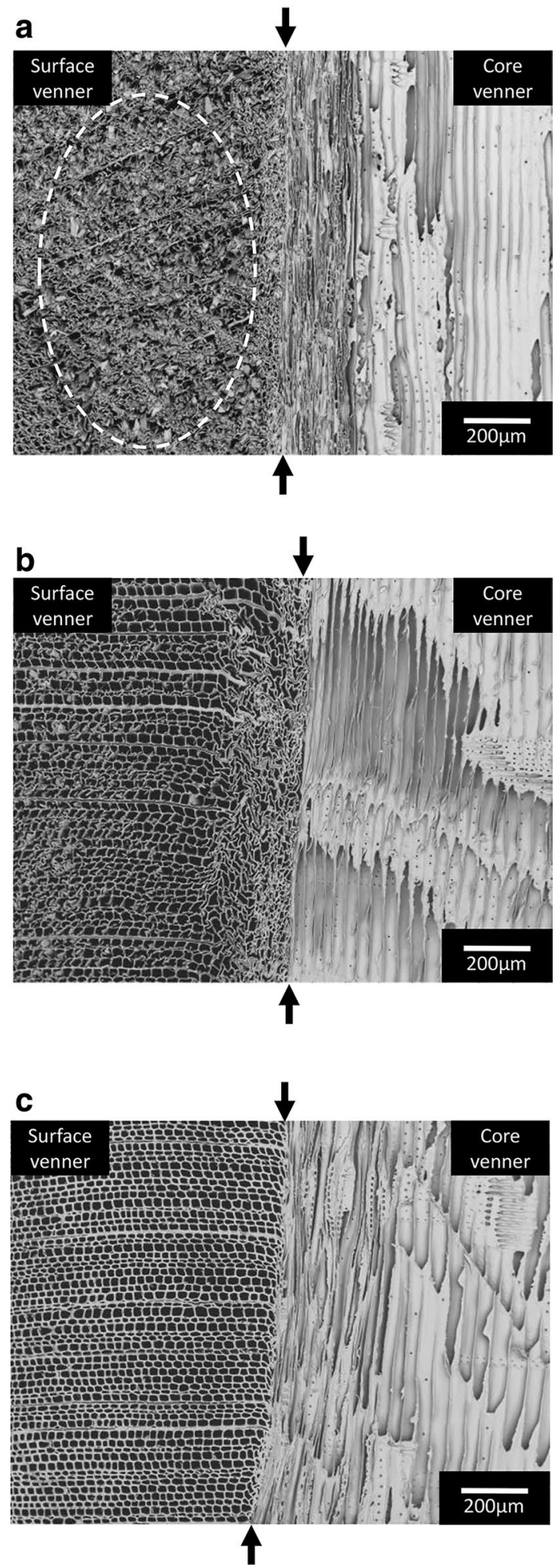

Fig. 5 SEM images of the boundary of the surface and the core veneers bonded with the Py2 (a), IM2 (b), EtPy8 (c) solutions (see Table 1 for the detailed composition of the adhesive solutions). The boundaries are indicated with the arrows for convenience

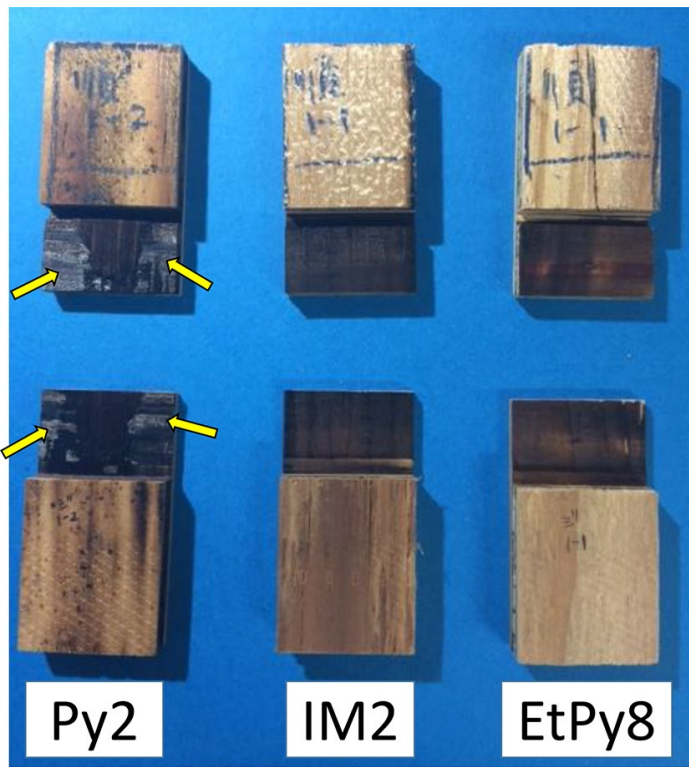

Fig. 6 Images of the fractured surface of the three-ply plywood specimens prepared with the Py2, IM2, and EtPy8 solutions after the shear bond strength test. The arrows show breaking of the veneers

Between the three ionic liquid solutions with the best amount of glucose, the [IM][Cl] solution with the ionic liquid/water/ glucose ration of 9/3/2 exhibited the best performance.

The SEM observation on the plywoods suggested that the ionic liquids softened the cell walls of the plywood and the cell walls were compressed during the pressing process. Entwining of the compressed cell walls and van der Waals force enhanced by the compression were considered to origins of the adhesive abilities. The compression was related to the penetration of the ionic liquid to the wood tissue during the pressing. The order of the intensiveness of the penetration was $[\mathrm{Py}][\mathrm{Cl}]>[\mathrm{IM}][\mathrm{Cl}]>[\mathrm{EtPy}][\mathrm{Cl}]$. The $[\mathrm{IM}][\mathrm{Cl}]$ caused the higher compression mainly around the boundary of the core and surface veneers than the $[\mathrm{EtPy}][\mathrm{Cl}]$ solution, so that the entwining and the enhancement of van der Waals force occurred effectively around the boundary in the case of the $[\mathrm{IM}][\mathrm{Cl}]$ solution. The $[\mathrm{Py}][\mathrm{Cl}]$ solution was spread so extensively to almost all parts of the veneers that it decreased the physical strength of the original veneers, ending up in lower bond strength of the resulting three-ply plywood.

\section{References}

1. Seddon KR (1997) Ionic liquids for clean technology. J Chem Technol 68:351-356

2. Ohno E, Miyafuji H (2013) Reaction behavior of cellulose dissolution in 1-ethyl-3-methylimidazolium chloride. J Wood Sci 59:221-228 
3. Miyata A, Miyafuji H (2014) Reaction behavior of cellulose in various pyridinium-based ionic liquids. J Wood Sci 60:438-445

4. Umemura K, Sugihara O, Kawai S (2013) Investigation of a new natural adhesive composed of citric acid and sucrose for particleboard. J Wood Sci 59:203-208

5. Swatloski RP, Spear SK, Holbrey JD, Rogers RD (2002) Dissolution of cellulose with ionic liquids. J Am Chem Soc 124:4974-4975

6. Miyafuji H, Miyata K, Saka S, Ueda F, Mori M (2009) Reaction behavior of wood in an ionic liquid, 1-ethyl-3-methylimidazolium chloride. J Wood Sci 55:215-219
7. Nakamura A, Miyafuji H, Saka S (2010) Influence of reaction atmosphere on the liquefaction and depolymerization of wood. J Wood Sci 56:256-261

8. Kilpeläìnen I, Xie H, King A, Granstrom M, Heìkkìnen S, Argyropoulos DS (2007) Dissolution of wood in ionic liquids. J Agric Food Chem 55:9142-9148

9. Mcbain JW, Hopkins DG (1925) On adhesives and adhesive action. J Phys Chem 29:188-204 